\title{
Los desiertos del otro lado: el desierto como espacio formativo en Ciudades desiertas de José Agustín y Road Story de Alberto Fuguet*
}

The Deserts of the Other Side: The Desert as a Formative space in Ciudades desiertas by José Agustín y Road Story by Alberto Fuguet

\author{
Catalina Forttes Zalaquett \\ Pontificia Universidad Católica de Valparaíso/FONDECYT \\ catalina.forttes@ucv.cl
}

Este trabajo estudia dos novelas de aprendizaje latinoamericanas que han reubicado el viaje formativo más allá de la frontera norte del subcontinente. Los "ya no tan jóvenes" protagonistas de las novelas Ciudades desiertas de José Agustín (México), y Road Story de Alberto Fuguet (Chile) huyen hacia los desiertos de Estados Unidos en busca de una épica que, mil veces vista en el cine, dé sentido a sus presentes desencantados. El objetivo de esta discusión es analizar las formas en que estas novelas resaltan la representación del cuerpo en tránsito por parajes desérticos como parte de un viaje formativo que pone a prueba aspectos fundamentales de lo que sus protagonistas entienden por identidad individual y nacional.

Palabras clave: Viaje formativo, afecto, desiertos de Norteamérica.

This article studies two Latin American coming-of-age novels that have placed their formative journeys beyond the northern border of the Latin America. The not-so-young protagonists of José Agustin's Ciudades desiertas (Mexico) and Alberto Fuguet's Road Story (Chile) flee towards the deserts of the United States in search of an epic seen many times in American films in order to give meaning to their disenchanted present. The objective of this study is to analyze the ways in which these novels represent bodies in transit through deserts as a formative process that questions what their protagonists understand as individual and national identity.

Keywords: Coming-of-age journey, Affect, Deserts of North America.

\footnotetext{
* Este trabajo es parte de mi proyecto Fondecyt de iniciación en la investigación titulado "Sobrevivir la megalópoli: adolescentes, masculinidad y medios en la novela de iniciación latinoamericana, 1960-2011" N 11121275, período 2012-2013, del cual soy investigadora responsable.
} 
Este trabajo estudia dos novelas de formación latinoamericanas que han reubicado el viaje formativo más allá de la frontera norte del subcontinente. Los jóvenes protagonistas de Ciudades desiertas de José Agustín y Road Story, la nouvelle de Alberto Fuguet huyen a los desiertos de Estados Unidos en busca de un espacio de reflexión que les permita vivir y descubrir dimensiones de sí mismos imposibles de imaginar en sus ciudades de origen ${ }^{1}$. El objetivo de esta discusión es analizar las formas en que el viaje formativo es ampliado hacia geografías que tensionan y expanden aspectos fundamentales de la identidad tanto nacional como de género. El desierto norteamericano otorga a los jóvenes representados en las novelas la posibilidad de someter a sus cuerpos a un estado excepcional, donde la interacción con los elementos, el tedio de la mirada que se pierde en el horizonte y la soledad de la carretera permiten observar las posibilidades sensoriales y afectivas de sus cuerpos y así ponerse en contacto con sus recuerdos, miedos y apetitos. La soledad será para los protagonistas un objetivo en sí, ya que como en todo rito de pasaje es necesario alejarse de la comunidad para descubrir las características y posibilidades del cuerpo y la psique. Los imaginarios fronterizos y desérticos no proveerán únicamente de geografía a la anécdota, sino que el gesto de cruzar la línea entre Latinoamérica y Estados Unidos se transforma en una experiencia iniciática en la que el joven pone a prueba la materia de la que se construye su interioridad y reflexiona en torno a cómo clasificarla. El paisaje desértico es así en estas narrativas espejo de una identidad que por medio del viaje busca definirse en términos nacionales y de género a partir de códigos entendidos a medias y la soledad autoimpuesta de la extranjería². Quisiera proponer que la búsqueda de los personajes desafía los marcos ideológicos y políticos de las clasificaciones del género al ubicarlo en el ámbito de lo afectivo, es decir, la forma en que el cuerpo reacciona ante la ausencia o presencia de otros cuerpos y los elementos que lo rodean. Los estados contemplativos que proporciona el viaje por geografías desérticas permiten la observación y calificación de los procesos del cuerpo y la identificación de pulsiones por años reprimidas por los contextos sociales de los que provienen los protagonistas. Los viajes representados en las obras ponen en perspectiva los imperativos biológicos tradicionalmente asociados al género como la maternidad o la violencia inherente a la masculinidad, para buscar en la experiencia de un cuerpo en tránsito resonancias coherentes con los espejismos de los deseos de los protagonistas.

Ciudades desiertas y Road Story son textos en los que el viaje formativo es desplazado hacia un espacio que mil veces visto en películas sirve de escenario para un proceso de autoconocimiento alejado de los elementos comunitarios que definen la identidad. Si hasta la primera mitad del siglo,

\footnotetext{
1 Este trabajo tratará Road Story como una nouvelle y por lo mismo el uso de cursivas en lugar de comillas al nombrarla. "Road Story" aparece como cuento largo en Cortos de Alberto Fuguet el 2006 y luego como novela gráfica en el 2007, sin embargo el texto que se trabaja aquí es el que aparece en Cortos.

2 La obra de José Agustín (México) y la de Alberto Fuguet (Chile) comparten un vínculo estético con el Estados Unidos mediatizado por el cine y el rock. José Agustín fue por años crítico de rock en tanto que Fuguet fue crítico de cine. Ambos pasaron parte de sus vidas en Estados Unidos y ambos han sido miembros fundadores de movimientos literarios en los que parte de la premisa fue aceptar las influencias de la cultura global y/o norteamericana en la producción cultural local.
} 
el espacio en el que se probaba el intelectual o el artista latinoamericano fue París, el lugar del deseo y el espacio para entrar en contacto con la sensibilidad de los tiempos se encuentra hace un rato ya en Estados Unidos. Si el "allá" de Rayuela fue el lugar donde el latinoamericano era expuesto a las maravillas y los horrores de la modernidad, en los textos que analizo el dinamismo de la ciudad moderna es reemplazado por la quietud del desierto norteamericano. El joven héroe popularizado por Hollywood es el referente del latinoamericano que desea emular su energía rebelde, atractivo físico y la gesta de una épica personal que dé sentido a sus presentes. La premisa es que el viaje formativo debe ocurrir en las fronteras de lo conocido, en lugares donde los códigos deben ser descifrados y donde la soledad hace revisar aquello que se da por sentado. El hecho de imaginar un viaje por los desiertos de Estados Unidos como el espacio para un proceso de autoconocimiento es producto de un archivo literario y cinematográfico rico en antihéroes reflexivos y solitarios que transitan por hoteles de carretera, bombas de autoservicio y diners donde sirven desayunos grasientos y café americano. Cabe rescatar que el escritor viajero como héroe se hace presente en las novelas por medio de figuras como Jack Kerouack cuyo On the Road sirve de intertexto al viaje de Simón en Road Story. En el caso de Susana, el programa al que se unirá en el medio oeste norteamericano ha alojado a los más grandes de las letras mundiales. El pueblo al que viaja, si bien no aparece en el mapa, cuenta con el aura de muchos otros escritores que antes que ella hicieron un hiato para escribir en medio de la planicie norteamericana.

La búsqueda de una nueva oportunidad en los desiertos norteamericanos aparece desde las narrativas de frontera del siglo XIX hasta los beatniks, ambas son parte de los imaginarios que contextualizan los viajes hacia la independencia y la adultez. Las imágenes del desierto de Estados Unidos han sido difundidas según Reinhart Koselleck como "espacios de experiencia" que proveen un "horizonte de expectativas" o un guion que invita a perderse para luego encontrarse. Antonio Damasio (2000) hace una contribución al entendimiento a los procesos formativos descritos por la imaginación literaria al equiparar la experiencia vital con la experiencia de lectura en la construcción de lo que llama el yo autobiográfico. Las experiencias pasadas de un "organismo individual" se archivan en lo que llama una memoria autobiográfica, la cual consta del registro de las reacciones afectivas que experimenta el cuerpo. El cuerpo responde emocionalmente a las imágenes que la experiencia vital y de lectura produce en nuestro sistema neuronal y al igual que todas las reacciones emocionales son calificadas por la mente. La experiencia mediada o directa se archiva en forma de memoria y estas son en consecuencia los elementos a partir de los cuales se construye la identidad. En esta línea, Slavoj Žižek extiende los alcances de la experiencia mediada y nos dice que es en la proyección cinematográfica que se materializan las pulsiones que definen el deseo. El cine es en su análisis la industria responsable de producir y circular los imaginarios del deseo -representaciones que dan cuenta de la realidad de nuestra psique individual y social-. Según Judith Butler el cine no solo enseña a desear, sino también enseña a personificar, escenificar y proyectar el género por lo que sirve como manual para la materialización del género en el cuerpo. Pienso que en el caso de los personajes de Road Story y Ciudades desiertas donde la apreciación del cine y las lecturas no solo invitan a los personajes a huir hacia los desiertos de Estados Unidos, sino 
que también los impacta de forma afectiva. Las canciones y las películas dan nostalgia, pena, escalofríos, euforia o incluso náusea y son las experiencias a partir de las cuales se va elaborando un yo autobiográfico que se construye por medio de elementos siempre representados dentro de las matrices del género y la cultura.

Interferidos por las imágenes mediatizadas de la experiencia viajera por los desiertos del suroeste norteamericano es que ambos protagonistas comienzan un viaje que tiene como objetivo resaltar sus figuras en contraste con el vacío del desierto y así poder proyectar sus paisajes psicológicos sobre un telón en blanco. Sin embargo, argumento aquí que el vacío que perciben los personajes se vincula con la incomprensión y la inconmensurabilidad que representa el espacio norteamericano para el viajero latinoamericano que ve desiertos en lugares que no puede decodificar. Es así como los centros comerciales, las calles sin peatones y el intrincado sistema de carreteras de Estados Unidos se transforman en desiertos en la mirada mexicana que en Ciudades desiertas viaja entre pueblos y ciudades del medio oeste de Estados Unidos. El desierto se representa en estas novelas como una construcción tanto ideológica como geográfica en la cual fallan o se neutralizan las formas de habitar aprendidas en espacios que se creen más orgánicos. Simón, el protagonista de Road Story, hace referencia a las vastas geografías y las carreteras del espacio estadounidense como el espacio ideal para este tipo de viaje: "si uno va a vivir entre paréntesis, por lo menos que haya espacio" (165).

Internarse en el desierto con el fin de ponerse a prueba es un viaje tanto de visionarios o misioneros como de exiliados o parias, pero lo que siempre es un denominador común la ejecución de un ejercicio físico y espiritual que se traduce en crecimiento o madurez psíquica. La escritora y naturalista norteamericana Mary Hunter Austin al intentar abarcar los desiertos del suroeste norteamericano de comienzos del siglo XX los define como espacios donde los límites no son establecidos por la ley, sino por la naturaleza de la tierra. Los desiertos ponen a prueba al cuerpo y a la psiquis por lo que son espacios donde se forma un héroe capaz de enfrentar los demonios de la carencia y superar la ausencia de signos civilizatorios comprensibles que lo orienten.

\section{El desierto con aire acondicionado y visa turista}

Es importante señalar que los desiertos de estos textos no se enfrentan de forma directa, es decir, los protagonistas no someten sus cuerpos a los rigores de los elementos de la misma forma en que los vaqueros, pistoleros, misioneros o migrantes que cruzan a pie o a caballo los desiertos en busca de un futuro, lo han hecho. Los desiertos de estas novelas se recorren en automóvil, con aire acondicionado y visa de turista o de académico extranjero. La velocidad y el aislamiento del automóvil les permite recorrer amplias geografías sin involucrarse con los contextos que construyen los paisajes. EI objetivo es el viaje en sí mismo, por lo que mientras más larga sea la ruta más se extiende el viaje y la narración.

A pesar de la relativa comodidad con la que viajan los protagonistas de estas novelas, no son exactamente turistas. Si bien salen a buscar espacios 
que conocieron en el cine de Wim Wenders o novelas de Jack Kerouac, lo que Simón, el protagonista de Road Story, y Susana y Eligio, los protagonistas de Ciudades desiertas, hacen es observarse a sí mismos viajar. En este sentido se parecerían más a la definición del etnógrafo que hace Marc Augé en Por una antropología de la movilidad, ya que este emplea un método de "observación sistemática, de manera solitaria y prolongada" (69). El etnógrafo pierde contacto con sus raíces y no se limita a estudiar un paisaje, sino que llega a poner a prueba su propia identidad al mantener un punto de vista externo a las realidades que observa. Podríamos decir que los personajes de las novelas de Agustín y Fuguet son etnógrafos de sí mismos, ya que la distancia que busca el etnógrafo la consiguen por medio del desdoblamiento que les produce viajar sin rumbo por los desiertos de Estados Unidos. La soledad permite exteriorizar la conciencia para así poder sostener una conversación con el yo autobiográfico y sintonizar con las pulsiones del cuerpo. Para Simón de Road Story no hablar con nadie es posible en Norteamérica, todo es self service y es factible pasar de un no lugar a otro (gasolineras, moteles, lavamáticos y la carretera misma) sin tener que articular palabra. Augé describe en Los no lugares. Una antropología de la sobremodernidad las dinámicas de los sujetos que transitan estos espacios como soledades dramatizadas por el hecho de que se hacen eco entre ellas. La ausencia de interacción humana le permite a Simón pensar como no lo ha hecho en años. El desierto le proporciona a Simón la posibilidad de estar en silencio y sentir que su soledad no incomoda a su familia o a sus amigos. Simón "se alegra de que nadie pueda saber lo que piensa. No sabría cómo justificarlo" (66). El desierto norteamericano ofrece lo que Baudrillard describe en América como un espacio en el cual se proyecta la mirada sin que encuentre nada que la refleje (6).

Susana de Ciudades Desiertas le explica su huida a su marido Eligio como una necesidad de alejarse de lo conocido y "circular por lugares donde nadie me conozca y renovar y reactivar mis procesos de crecimiento (...) necesitaba estar sola, ver las cosas desde la perspectiva de mi propia individualidad, sin tener que compartir contigo, o con quien fuera" (33). Susana busca en su viaje no solo un antídoto contra la inercia, sino que situaciones emocionales que induzcan a la creatividad.

Si para Georg Lukács la inserción en lo social es el objetivo de los protagonistas de la novela de formación tradicional y para lo cual el joven deberá negociar su interioridad con la realidad, en estas novelas vemos a protagonistas liminales que por un lado no desean la inserción en una sociedad que evalúan con escepticismo, en tanto que por otro temen al desarraigo. Los privilegios y comodidades de los contextos sociales de los que provienen los protagonistas de Fuguet y Agustín no les han permitido conocerse y por el contrario sienten que el fracaso se asocia a la pasividad y la inercia que involucra la estabilidad de los rituales pequeño burgueses a los que han sometido a sus cuerpos. Así el viaje hacia los desiertos del norte se plantea como una huida del trabajo rutinario y poco desafiante, la inercia y la anestesia afectiva.

Sin embargo, es precisamente la condición de privilegio social de los protagonistas de estos textos la que determina una relación con los Estados Unidos, que no invoca el imperativo del sueño americano en términos de 
progreso económico, pero sí en la idealización del espacio como un lugar donde explorar las libertades individuales. La mitología globalizada del espacio norteamericano como el lugar de la reinvención y la segunda oportunidad se concretiza en la ubicación del viaje formativo en sus carreteras y moteles. El paréntesis que rompe con la inercia de la vida en México D.F. o en Santiago de Chile es imaginado como una "Road Movie" personal, pero no como un destino permanente o una vacación, sino como un hiato que proporciona el silencio necesario como para aprender a percibir las pulsiones y las intensidades de sus cuerpos.

Los textos que aquí se analizan cumplen con una de las premisas básicas de la novela de formación según Franco Moretti, ya que presentan a jóvenes que gozan del privilegio de no tener que trabajar y que, por lo tanto, pueden incluso fuera de las etapas tradicionalmente formativas iniciar un viaje de autodescubrimiento. De esta manera tanto la obra de Agustín como la de Fuguet desplazan el imperativo de ubicar el viaje formativo dentro de la adolescencia, para ubicarlo en el momento en que los protagonistas están a punto de dejar de ser jóvenes. Llama la atención la forma en que estos textos han desplazado problemáticas propias de los procesos formativos hacia la adultez. Los protagonistas son así treintañeros que asumen el desafío, quizás regresivo de no conformarse a los programas vitales impuestos, hacer un alto y asumir las consecuencias de su retiro.

El monólogo interior del sujeto que atraviesa el desierto se representa en Road Story por medio de viñetas que revelan los pensamientos de Simón a medida en que va enfrentando distintos escenarios. De forma no lineal le revela al lector la historia de un fracaso matrimonial, que gatilla una crisis en la que Simón cuestiona la validez de todas las relaciones y dinámicas sociales de las que un joven profesional acomodado debería participar. Simón un hombre en sus treintas y supuestamente adulto vuelve a llenarse de la suspicacia adolescente que ve hipocresía y falsedad en todo lo que lo rodea y sobre todo en figuras de autoridad como la de su padre que además es el dueño de la empresa para la que trabaja. Road Story es el relato personal de una huida en la que se abandona la geografía nacional pero no necesariamente su territorio psicológico, un paisaje donde coinciden figuras patriarcales que hacen sentir el peso de sus tradiciones. Simón Rivas, al igual que la mayoría de los perdidos de Fuguet, ha crecido en el privilegio, sin embargo, no se siente en deuda con este mundo y es capaz de sorpresivamente dejarlo todo para comenzar un viaje del que quizás no regrese. Simón estafó a su empresa y a su familia. Simón, antes de la estafa, debía exportar o globalizar el pescado de su padre, por lo que tuvo que viajar a Estados Unidos en un viaje de negocios, pero no volvió. Se quedó con suficiente dinero como para viajar un tiempo, en Los Ángeles se arrendó un auto y comenzó un recorrido por los desiertos del sudeste norteamericano.

Resulta interesante que el primer gesto de liberación de aquello que lo ancla a su origen sea desprenderse de la ropa que cubría su cuerpo y lo codificaba dentro de una clase social. Como señal de que se embarca en un viaje exploratorio Simón bota en un tacho los trajes y camisas de marca y decide no ducharse hasta que la camiseta que se compró en una tienda de ropa usada esté tan saturada de su sudor que la tenga que botar. Simón 
necesita olerse, conectarse con sus fluidos, con su cuerpo, saber quién le dice su cuerpo que es: "Su propio hedor lo embarga y lo mantiene despierto, alerta, vivo" (172). Esta escena puede también ser leída como un ejercicio de ascetismo en el cual el cuerpo se entrega a la privación como una forma de exorcizar aquellos elementos que lo asocian con estructuras corruptas o que le impiden acercarse a su verdad.

Simón tiene que ser consecuente consigo mismo y poner freno a la inercia que ha caracterizado la forma en que toma decisiones porque "si uno no es capaz de ser leal con uno, de cumplir sus propias promesas ¿qué se puede esperar de los demás?" (175). Simón nunca ha podido articular una narrativa que dé forma a sus emociones, ya que siempre ha mantenido las relaciones afectivas a una distancia que le permita no hacer esfuerzos comunicativos. Es tan solo tras el volante y escuchando estaciones de radio tejanas que se da cuenta que nunca le ha dicho a nadie lo que siente. Su cuerpo sufrió los estragos de un cáncer, le sacaron un testículo, su mujer lo dejó y sin embargo todas estas experiencias corporales nunca fueron articuladas como sentimientos y compartidos con nadie: "Cuando le dio el cáncer y le sacaron un testículo, no se quebró. No se volvió loco. Ni siquiera los hizo gastar dinero en sicólogo. Sus padres no se pueden quejar. Todos sus hermanos lo han hecho sufrir mucho más que él" (169). Simón no conoce las palabras para expresar el dolor, por años se las ha pedido prestadas a las películas y ha llegado al punto en que ante el cúmulo de emociones y la ausencia de palabras para expresarlas, llora hasta con los dramas de las cuasicelebridades faranduleras. Sus emociones lo traicionan, se siente feminizado por sus circunstancias por lo que la única forma de sufrir es huyendo o desapareciendo. Simón no sabe cómo es que un hombre de treinta y cinco años asume que se ha convertido en lo que es y no en aquella persona que su familia y su contexto esperaban que fuera. En sus círculos y en su familia no hay modelos masculinos para el fracaso y poca paciencia con los perdidos.

En Ciudades desiertas Susana decide escapar de su país y su matrimonio por miedo a la rutina que se ha instalado en su vida de esposa y profesora. Susana lo explica de la siguiente manera: "tú actuabas como siempre y yo escribía y daba mis clases, teníamos para comer y todo y sin embargo éramos la pura inercia (...) en esos momentos es cuando se necesita un acto decisivo, una verdadera revolución para poder saber qué está pasando" (114). Para Eligio, ese acto decisivo sería el de tener un hijo; sin embargo, Susana no sabe si esto es algo a lo que ella quiere entregarle el cuerpo y la vida. La rebeldía de convertirse en escritora y casarse con un actor de clase trabajadora ya es rutina, y la literatura no se alimenta de los ritos cotidianos. La llegada de un hijo es para una mujer y escritora como Susana la forma de exacerbar el aislamiento y la inercia que caracteriza el matrimonio: "Era imposible precisar en qué momento todo se había ido cubriendo de veladuras finísimas, casi imperceptibles, que la aislaban herméticamente de la realidad y que poco a poco fueron envolviéndola hasta momificarla (3). Para Susana "la vida es pésima literatura" (31) por lo que al igual que Simón huye en busca de otras intensidades a Estados Unidos. El viaje de Susana tiene un poco más de estructura que el de Simón puesto que comienza con una estadía en un programa internacional de escritores ubicado en un pueblo norteamericano que solo aparece en mapas locales. 
Tanto Simón como Susana inician su viaje producto de un quiebre en su relación amorosa y la consiguiente necesidad de definir roles de género y nociones identitarias que la relación puso en crisis. En el caso de Simón, la mujer con la que habían decidido no tener hijos lo abandona por un amigo cercano, en tanto que para Susana las exigencias de género tradicionales como la maternidad y el sustento de una armonía doméstica la obligan a huir para redescubrir sus capacidades creativas tanto literarias como biológicas.

Si leemos la huida de Susana en términos afectivos cobra sentido que una de las primeras experiencias que busque en Estados Unidos sea la exploración sexual con desconocidos. Susana al igual que Simón necesita descubrir qué le pasa cuando somete a su cuerpo a experiencias desconocidas e incluso extremas. Susana comienza un proceso de experimentación sexual y pronto establece una relación con un escritor eslavo que casi no habla y que es representado como poseedor de un cuerpo enorme de características animales y por supuesto un miembro que debido a su enorme tamaño transforma los encuentros amorosos en experiencias dolorosas. El objetivo es descubrir y codificar las resonancias e impresiones que dejan los encuentros entre los cuerpos para luego contrastarlas con la idea que Susana tiene de sí misma. Su cuerpo es llevado al límite e incluso permite que su amante la golpee, para así descubrir cuanto es capaz de soportar. Este tipo de ejercicio adquiere en el caso de Susana relevancia dentro de su cuestionamiento en torno a la maternidad -un proceso biológico con tremendas implicancias afectivas- que ha puesto su relación matrimonial y su vida en crisis.

Eligio la va a buscar a Estados Unidos, pero a diferencia de Simón cree que la respuesta al abandono está en la mujer que lo abandonó y no dentro de sí mismo. El tipo de relación de pareja que actualiza Eligio es la de la codependencia melodramática anclada en los roles tradicionales de género que expresan los boleros y las telenovelas en las que trabaja como actor:

Ya te dije que vine hasta el culo del mundo porque desde que te conocí, como dice la canción, supe que tú eras mi dama, la que me correspondía hasta los últimos segundos de mi vida, por la que tendría que luchar contra mil obstáculos hasta que tú entendieras que somos lo mismo tú y yo, y que huir de mí es en realidad huir de ti (35).

Llama la atención que Estados Unidos sea el "culo del mundo", es decir, en la mirada de Eligio un espacio sobre el cual no vale la pena detenerse, un lugar remoto de lo que él entiende debe ser el mundo; un desierto donde las dinámicas sociales se han deteriorado al punto de quebrar su organicidad "natural". Susana debería querer un hijo y no sentir que es una esclavitud: "Susana, carajo, te estás meando fuera de la bacinica ¿cómo puedes ser tan insensible? Tener un hijo no tiene por qué ser una ruina, tiene que ser un ondón (...) tal como lo indica la Madre Natura" (36).

Eligio se escuda detrás de un papel tradicionalmente femenino. No solo sigue a su mujer, sino que es también el que se preocupaba de las tareas domésticas del hogar que compartían. Sin embargo, esta dinámica es para Eligio una estrategia para no hacerse vulnerable a los reclamos propios de 
una mujer cerebral y enfocada en su escritura. Eligio justifica su feminización en términos extremadamente machistas:

desde un principio jamás te jodí con que trapearas o plancharas o barrieras, te juro que hasta miedo me daba cada vez que surgía un pleito entre nosotros, y por eso miles de veces yo fui el pendejo que lavó trastes y barrió la alfombra y tendió camas (...) siempre tuve terror de que me fueras a acusar de macho mexicano y exactamente eso es lo que ahora me estás diciendo, iqué país! (34)

La huida a Estados Unidos convierte a Susana en la mujer que le puede decir "macho mexicano" en términos derogatorios y por lo tanto se hace imprescindible para Eligio volver a México, abandonar el "culo del mundo" y sus desiertos habitados por zombies que no conocen las dinámicas del melodrama mexicano.

Susana es representada como producto de la burguesía mexicana, hija de un médico y bien educada, en tanto que Eligio es de origen trabajador y es constantemente racializado en la descripción de Agustín. Su atractivo radica tanto en su carisma y desfachatez como en su piel cobriza y lampiña y su rostro de ángulos indígenas. Estas son características que no pasarán desapercibidas por la mujer norteamericana que Agustín representa como carente de raíces e historia y en una desesperada búsqueda de relaciones con sujetos que la hagan sentir cosmopolita y que active sus fantasías de rozar aquellos imaginarios estudiados en cursos de literatura hispanoamericana. La mirada prejuiciada de la vida académica norteamericana de Agustín se encarna en Irene, una estudiante norteamericana que acompaña sin reclamos a Eligio en la búsqueda de Susana por las carreteras del medio y sudoeste norteamericano. Irene no tiene problemas en ser una compañera sexual y de ruta, pero en lugar de agradecer los favores, Eligio la describe como una mujer sin arraigo que "solo podía entender en abstracto cosas como la patria, pero jamás en concreto" (63-64). Eligio proyecta así su desprecio por las libertades sexuales que se ha tomado Susana sobre Irene.

Juntos Susana y Eligio representan la amalgama cultural del artista mexicano contemporáneo y esta es la que Agustín hace viajar a Estados Unidos en busca de definición. Solo al contrastarse con el entorno norteamericano -que no se esfuerzan por comprender- es que tomarán conciencia de aquello que los define como mexicanos y como pareja. Para Eligio Estados Unidos no es solo un desierto de ciudades vacías donde no transita un alma por la calle, sino también un país senil que vampiriza la energía de los inmigrantes jóvenes:

México es puro surrealismo, la pura pachanga, es una vergüenza, iqué país! Pero la gente está mucho más viva que aquí y está aprendiendo a expresarse, a conocerse, a no tenerse miedo (...) aquí en cambio, y no agraviando a los presentes, la gente se han convertido en robotcitos, se les está muriendo el alma, se han vueltos viejitos cuando en realidad son un pueblo bien joven, qué horrible ser anciano antes de tiempo (62-63). 
La relación binaria de un México adolescente, joven y revoltoso y un Estados Unidos viejo donde los sueños alcanzados adormecen a sus ciudadanos coincide con la noción de utopía alcanzada que discute Baudrilliard en America. Ambas lecturas de Estados Unidos coinciden en que el esfuerzo de los norteamericanos está en sostener la utopía y que en esto no hay dinamismo ni creatividad. Tanto Agustín como Baudrilliard insisten en describir el espacio Norteamericano como desértico, aun cuando las geografías que recorren incluyen ciudades y espacios de alta densidad demográfica como Chicago, Los Ángeles y Albuquerque. Hay también en estos autores un deseo por confirmar los estereotipos proporcionados por la industria cultural hollywoodense. En palabras de Baudrilliard:

The inhumanity of our ulterior, asocial, superficial world immediately finds its aesthetic form here, its ecstatic form. For the desert is simply that: an ecstatic critique of culture, an ecstatic form of disappearence (5).

La relación de Fuguet con los Estados Unidos es más matizada, ya que hay amor por el universo referencial norteamericano de las películas, los libros y la música. Así lo aclara junto al escritor Edmundo Paz Soldán en el prólogo a Se habla español: "¿puede alguien hoy -de verdad, sin posar- no tener nada que ver con USA? Quizás pueda uno quererlo, pero es poco menos que imposible lograrlo. Estados Unidos -lest's face it- está en todas partes. Es una de las materias de nuestros sueños" (12). Simón cree "que los Estados Unidos han colonizado su inconsciente. Recorriendo el Oeste, Simón siente que ha estado en lugares que le resultan familiares" (171). Road Story lleva como epígrafe una cita a On the Road de Jack Kerouack, hay un intertexto con la película The Passenger (1975) de Michelangelo Antonioni y una cita escenográfica a la película Bagdad Cafe (1987) de Percy Adlon ${ }^{3}$. El Estados Unidos de las películas no es antagónico, sino que el telón de fondo sobre el cual se proyecta una épica personal. De la misma forma que el Oeste Norteamericano se imaginaba desde los pueblos decimonónicos de Nueva Inglaterra y los cowboys y pioneros del Oeste montaban una épica nacional sobre una tierra que encarnaba tanto sus miedos como ambiciones de la modernidad, para Fuguet el desierto representado por Wim Wenders, Percy Adlon, los westerns y los Beatniks transforma en héroes a quien se aventure a internarse en ellos.

Los desiertos son en palabras de Baudrillard en America, un espacio suspendido en la eternidad donde aquello que ha construido el hombre se neutraliza ante la inmensidad de una geografía milenaria y sobrecogedora. El narrador de Road Story hace eco al crítico francés:

Simón mira el cielo y siente que es tan grande que se tiene que agachar. Acá todo es tan exagerado, inmenso, y el sol te quema y te seca incluso cuando estás a la sombra.

\footnotetext{
3 En el caso de The Passenger de Antonioni, un periodista de la BBC interpretado por Jack Nicholson recorre el desierto del norte de África en tanto que en Bagdad Cafe de Adlon una turista alemana viaja con poco rumbo por el desierto norteamericano. En ambos casos los desiertos les proporcionan a los protagonistas la posibilidad de autoconocimiento y reinvención.
} 
Esta es una tierra para gente que no se asusta, piensa que no les teme a las geografías y pasiones que excedan a la escala humana (156).

Cuando Simón se enfrenta al gran cañón y su inmensidad atemporal siente vértigo, vomita, se acuerda de su matrimonio, pero son precisamente las proporciones del paisaje las que ponen su pequeño drama de niño burgués en perspectiva. La reacción de Simón es continuar el viaje dejando que el pasado se disuelva en su espejo retrovisor. En un impulso adolescente que enfatiza los aspectos regresivos de un viaje formativo postergado a la adultez, se impone como única meta llegar al hotel Congress en Tucson donde "solo aloja gente que no tiene apuro o le gusta el rock. Ambas cosas van juntas" $(185)^{4}$. Para Susana y Eligio las ciudades desiertas que ven desde las carreteras son el reflejo del vacío sobre el cual se sostiene su matrimonio. La amplitud de las planicies nevadas del medio oeste norteamericano invitan, al igual que el desierto del suroeste que recorre Simón, a desaparecer en el silencio. Susana y Eligio no viajan juntos, sino que se persiguen por los laberintos carreteros del medio oeste para finalmente enfrentarse el uno al otro en un auto atascado en la nieve interminable. La inmensidad de la blancura desnuda la relación al quitarle todos los espejos que le devuelvan a la pareja una idea de lo que son. Susana, que ha perdido la empatía por su perseguidor, continúa su viaje y deja a su marido dormido en un auto rodeado de un desierto que no ofrece un solo signo al cual aferrarse.

\section{El desierto como paréntesis}

Ambos viajes se plantean como delimitados en el tiempo y el desierto es el espacio del paréntesis. La vida real y sus exigencias está en Santiago o en el D.F. y la estadía en Estados Unidos, si bien es necesaria, es también transitoria. El paréntesis sostiene un grado de autismo, de ensimismamiento que el lugar de origen y quizás el mundo latino no permite. El estereotipo del latino intenso y extrovertido encarnado por Eligio cobra un carácter nacional en Road Story cuando Simón cruza de El Paso a Ciudad Juárez acompañado por Adriana, una mujer hispana que conoció en Tucson. Al encontrarse con México, Simón piensa que es menos pobre de lo que imaginaba y brutalmente real. Para Simón México no podría ser un paréntesis. En Juárez el silencio de las autopistas y los hoteles de paso es reemplazado por ruido y gente. La incomodidad ante la interacción obligatoria con el entorno hace a Simón más extranjero en México que en Estados Unidos donde el movimiento continuo lo ha hecho invisible. Simón sabe que su paréntesis no será para siempre, le falta coraje, él no es como su tío Gaspar Rivas (el miembro más enigmático y vetado de la familia), quien desapareció en Estados Unidos ${ }^{5}$. Para desaparecer hay que hacer sufrir a mucha gente y Simón no está dispuesto

\footnotetext{
4 El hotel Congress ya ha sido descrito antes en Por favor, Rebobinar de Fuguet como el lugar donde se aloja una temporada Josh Remsen, ídolo, poeta y cantante existencialista, inconformista y cool descrito también en Mala onda. Simón de Road Story actualiza la anécdota de Remsen en el relato de un fan que se compromete llegar al Congress para darse un baño de tina como el que sale en la portada del disco de Remsen.

5 Fuguet desarrolla la historia del tío Gaspar en Missing: una investigación, texto de no ficción novelada publicado por Alfaguara en 2010.
} 
o no se atreve. A pesar de esto, cruzando el desierto concluye que su tío está por ahí, que no está muerto como dicen muchos, sino que no cerró el paréntesis: desapareció.

El paréntesis de Simón se cierra solo en el momento en que logra establecer comunión con otra persona. Adriana, una chica que se une a su viaje de forma fortuita, le va a exigir no solo interacción, sino que también compromiso. Simón siente en un comienzo que la lleva "a cuestas" (197) que interrumpe sus planes de vagar/escapar sin brújula y le asusta la intimidad que rápidamente desarrolla con una mujer que apenas conoce. Con Adriana se cuentan historias sobre sus pasados, pero no son más que eso, ficciones sobre quienes les hubiera gustado ser o eventos que darían sentido a una huida hacia el desierto. Sin embargo, Simón y Adriana hacen el ejercicio de construir por medio de sus mentiras a los personajes que realmente quisieran ser. El viaje de Adriana no es un paréntesis, su vida es el desarraigo, la carretera, los trenes y los hoteles de poca monta, en tanto que Simón por mucho que no le guste, tiene un mundo al cual volver. Adriana funciona como personaje espejo de Simón, ella representa aquello en lo que Simón podría convertirse si renuncia por completo a la vida que dejó en pausa en Chile. Adriana lleva mucho tiempo entre paréntesis y le revela a Simón la tragedia del desarraigo. Adriana encarna la tragedia del ser fronterizo que al ocupar el espacio intermedio de la ilegalidad desaparece. Pero ser ilegal no es igual que ser invisible y a pesar de que Adriana ha aprendido a escabullir la ley con sabiduría pícara es un ser autodestructivo y solitario que ha renunciado a la posibilidad de la inserción social. Adriana es el opuesto al "híbrido feliz" y vive demasiado cerca de la muerte, ya que padece de cirrosis hepática ${ }^{6}$. Simón se entera de esto al encontrarla en un charco de sangre y pagar una carísima cuenta de hospital. Simón la salva y con esto rompe su inercia. El impactar la vida de alguien de esa forma inevitablemente cambia la propia y Simón comienza a cerrar el paréntesis.

Uno de los aspectos más productivos de la figura de Adriana resulta del hecho de que fue Adrián Pereyra en "La verdad o las consecuencias", la primera versión del cuento publicada en la antología McOndo en 1996. Adrián y Adriana son sorprendentemente parecidos -a excepción del género, la nacionalidad y algunos datos biográficos son el mismo personaje-. Ambos comparten las mismas circunstancias y las interacciones con Simón (Pablo en la primera versión) son casi idénticas. Fuguet no se preocupa demasiado en feminizar al personaje. Un ejemplo de esto es que la segunda vez que Simón divisa a Adriana en las inmediaciones del Congress es pegándole a un tipo en el estómago y la nariz, escena que obviamente cobra más fuerza cuando

\footnotetext{
6 El "híbrido feliz" es el concepto con el que el crítico tijuanense Heriberto Yépez en Made in Tijuana duramente critica la metáfora de hibridación catapultada al mundo académico por el sociólogo argentino Néstor García Canclini en su ya célebre Culturas híbridas. Para Yépez el problema no es necesariamente entender la frontera, y en su caso Tijuana, como un laboratorio posmoderno de inconmensurable fuerza creativa, lo que lo incomoda es el interminable "sampleo" del término que ha simplificado, frivolizado y por sobre todo despolitizado las problemáticas de la frontera. El "híbrido feliz" que reconoce Yépez en la jerga académica oscurece la relación hegemónica de una cultura/nación sobre otra al plantear un sujeto que fusiona identidades, nacionalidades y culturas simétricamente (11-18).
} 
la agresora es mujer. Adriana es una mujer que produce en Simón tanto atracción como repulsión, ambivalencia que se origina en la forma en que invierte las categorías de género7. Adriana por un lado proyecta la fragilidad de un hombre solitario y algo agresivo, en tanto que, por otro, demuestra la hiperadaptabilidad con la que Fuguet caracteriza a la mayoría de sus mujeres. Adriana presenta rasgos del hombre que Simón no se atreve a ser: un hombre sin miedo al desarraigo que construye su vida sobre la marcha. El hecho de que Adriana haya tenido una vida literaria anterior como hombre puede ser indicio de que quizás una de las claves para la estabilización de una masculinidad perdida es la aceptación de los elementos femeninos de esta. Es posible que Simón por medio de Adriana haya dejado de ser un perdido y se haya convertido en un viajero.

En Ciudades desiertas la persecución de los esposos por las tierras del norte es también un paréntesis que comienza y termina en México D.F. Eligio perdió a Susana en Estados Unidos, la encuentra y la vuelve a perder. Eligio volvió a casa solo, pero Susana se aparece a los pocos meses. La escena con la que cierra la novela muestra a Eligio contento preparándose para ir a un ensayo cuando aparece Susana que aún tiene las llaves del departamento. Susana declara: "Regresé porque ya se había terminado mi tiempo de andar de nómada, regresé porque eso es lo que tenía que hacer y eso hice" (115). La última vez que se vieron fue enterrados en la nieve de las planicies del medio oeste y ahora Susana le dice que está embarazada de él. Eligio no le cree, cuestiona su paternidad y solo la acepta de vuelta en su vida después de reducirla simbólicamente al modelo tradicional de feminidad. Si bien lo que ejerce es violencia, esta se representa de forma cómica e incluso erótica, ya que le baja los calzones y le da nalgadas obligándola a confesar su amor por él. La escena revela que la pareja puede replantearse en México solo en términos tradicionales y el embarazo confirma que la aventura de Susana se instala en el pasado como un paréntesis en el cual ella descubrió su verdadera esencia la de mujer y madre. Si bien Elena Poniatowska en el prologo a Ciudades desiertas la describe como una de las primera novelas "antimachistas" habría que recalcar que el conflicto de la novela se resuelve en términos extremadamente tradicionales y que la pareja se proyecta únicamente a partir de roles de género muy poco dinámicos. Es más el cuerpo de Susana es representado por Agustín en una serie de situaciones abusivas, ya sea por medio de golpes, sexo doloroso o frío. Podríamos establecer que en lugar de permitirle a Susana una búsqueda afectiva Agustín la castiga por su osadía. El resultado de una búsqueda sexual femenina es en la novela el embarazo, no la forma de evitarlo.

Los textos que he analizado se ajustan parcialmente a la premisa de la novela de formación tradicional en el sentido en que cumplen con revelar el camino hacia la madurez y la integración. El descubrimiento es el haber conocido el vértigo de la soledad y el desarraigo, condiciones que en la

7 La figura de Adriana encaja en un marco femenino que Fuguet ha explorado en obras anteriores. En novelas como Mala onda y Por favor rebobinar las mujeres que los protagonistas masculinos respetan debido a su autenticidad y fuerza tienen rasgos masculinos. Recordemos a Flora Montenegro, Ximena Santander o Ignacia Urre, todas mujeres con "demasiada personalidad" como para encajar en los marcos de género de su época. 
adolescencia no producen el mismo terror que individuos que, ya en sus treintas, no son capaces de vislumbrar un "afuera" al mundo que conocen. Tanto Road Story como Ciudades desiertas cierran con protagonistas que han desarrollado una nueva disposición hacia sus contextos de origen. $\mathrm{Ni}$ Simón ni Eligio ni Susana son "outsiders", por el contrario, vuelven fortalecidos a los lugares que los expulsaron. Los desiertos que recorrieron son los que esperaban conocer debido a que sus viajes no tenían como objetivo integrarse a un espacio y realmente conocer un lugar, sino el tránsito en sí. Moverse por los desiertos ya vistos en películas y novelas fue la forma en que estos personajes eligieron para estar solos y es dentro de la soledad de la ruta que encontraron la compañía, la capacidad y necesidad de integrar otra persona a sus vidas. Simón encuentra a Adriana y Susana vuelve con Eligio porque ha encontrado la maternidad. Prefiero pensar que en lugar de ser resoluciones conservadoras, los cierres de la novela explicitan la necesidad que tiene el cuerpo y la psiquis del otro. Que mientras más uno se observa más se da cuenta de que la importancia del otro cariñoso para la supervivencia y la integración. También rescato que los textos de Agustín y Fuguet les otorgan a treintañeros la posibilidad de abrir un paréntesis donde perderse y encontrarse. Ser madre es una decisión y tiene poco de natural para Susana una mujer que hasta ese momento ha dedicado toda su fuerza creativa a su escritura y en el caso de Simón, recuperarse de un divorcio y una traición no es algo que un hombre haga con facilidad solo por el hecho de ser hombre. Agustín y Fuguet ponen en estos textos a sus personajes a explorar emociones no asociadas a las nociones de género tradicionales para revelar que enfrentados a la crudeza de las emociones a veces la respuesta innata es huir hacia un espacio que permita visualizarlas, calificarlas para así poder incorporarlas a una narrativa biográfica.

\section{Obras citadas}

Agustin, José. Ciudades desiertas. México D.F.: Edivisión, 1982.

Augé, Marc. Por una antropología de la movilidad. Barcelona: Gedisa, 2007. Los no lugares. Una antropología de la sobremodernidad.

Austin, Mary Hunter. The Land of Little Rain. New York: Penguin, 1997.

Baudrillard. America. Verso: New York, 1989.

Damasio, Antonio. Looking for Spinoza: Joy, Sorrow, and the Feeling Brain. Harcourt, 2003.

Fuguet, Alberto. Cortos. Alfaguara: Santiago, 2004. . Road Story. Alfaguara: Santiago, 2007.

Fuguet, Alberto y Sergio Gómez, eds. McOndo. Barcelona: Mondadori, 1996.

Fuguet, Alberto, Paz-Soldán, Edmundo, eds. Se habla español: Voces Latinas en USA. Miami: Alfaguara, 2000.

García Canclini, Néstor. Culturas híbridas. México, D.F.: Editorial Grijalbo, 1990.

Koselleck, Reinhart. Futuro pasado: para una semántica de los tiempos históricos. Barcelona: Paidós, 1993.

Lukács, Georg. The Theory of the Novel: A Historico-philosophical Essay on the Forms of Great Epic Literature. Cambridge: MIT press, 1971.

Moretti, Franco. The Way of the World: The Bildungsroman in European Culture. London: Verso, 1987.

Yépez, Heriberto. Made in Tijuana (crítica y crónica). Mexicali: ICBC, 2006. 


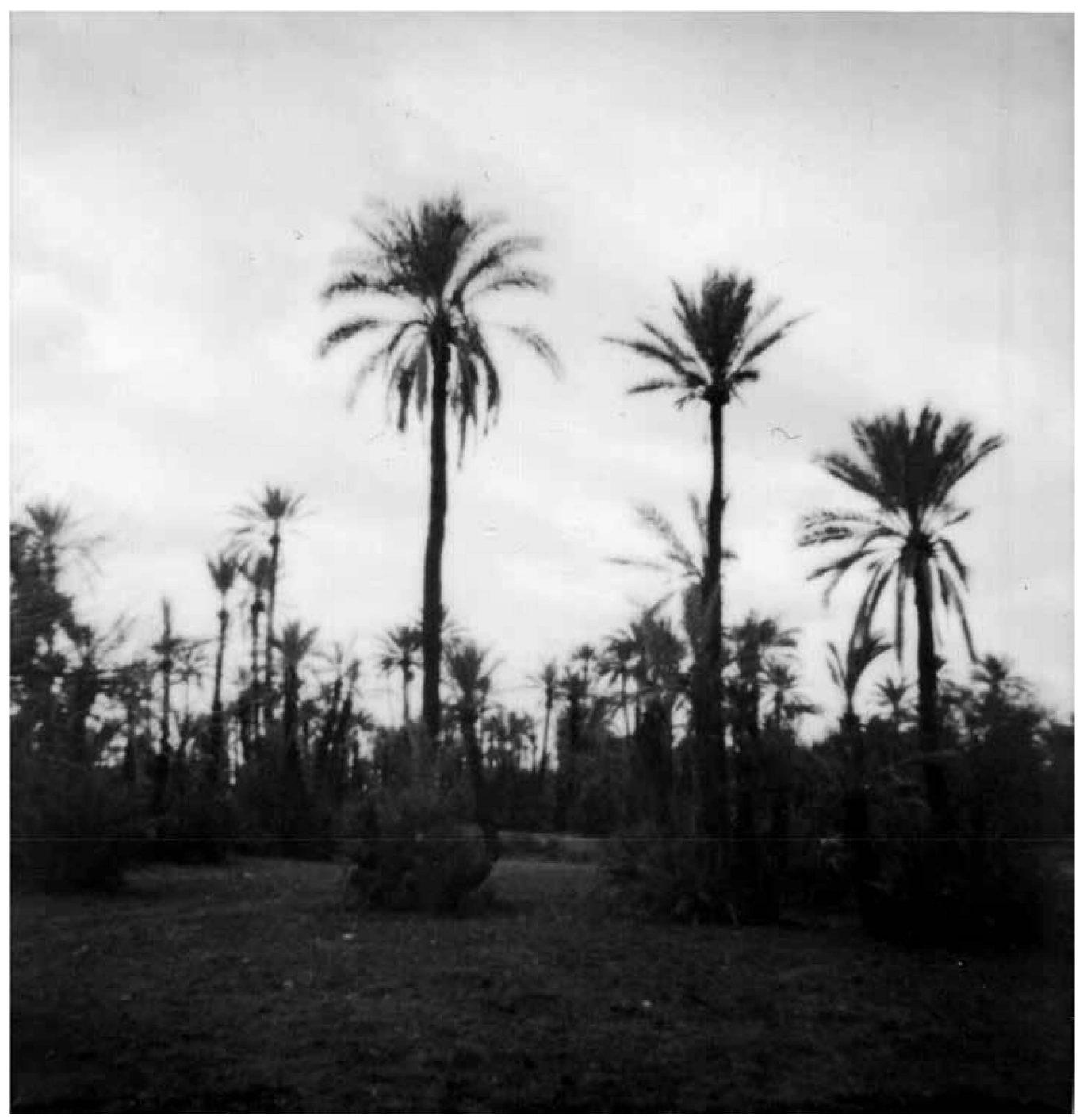

Marruecos.

(C) Pablo Chiuminatto, Serie Desiertos, 2000. 